\title{
Science data collection with polarimetric SAR
}

\section{Dall, Jørgen; Woelders, Kim; Madsen, Søren Nørvang}

\section{Published in:}

Proceedings of the International Geoscience and Remote Sensing Symposium

Link to article, DOI:

10.1109/IGARSS.1996.516315

Publication date:

1996

Document Version

Publisher's PDF, also known as Version of record

Link back to DTU Orbit

\section{Citation (APA):}

Dall, J., Woelders, K., \& Madsen, S. N. (1996). Science data collection with polarimetric SAR. In Proceedings of the International Geoscience and Remote Sensing Symposium: Remote Sensing for a Sustainable Future (Vol. Volume 1, pp. 276-278). IEEE. https://doi.org/10.1109/IGARSS.1996.516315

\section{General rights}

Copyright and moral rights for the publications made accessible in the public portal are retained by the authors and/or other copyright owners and it is a condition of accessing publications that users recognise and abide by the legal requirements associated with these rights.

- Users may download and print one copy of any publication from the public portal for the purpose of private study or research.

- You may not further distribute the material or use it for any profit-making activity or commercial gain

- You may freely distribute the URL identifying the publication in the public portal 


\title{
Science Data Collection with Polarimetric SAR
}

\author{
J. Dall, K. Woelders and S. N. Madsen \\ Danish Center for Remote sensing, Department of Electromagnetic Systems \\ Technical University of Denmark, B348, DK-2800 Lyngby, Denmark \\ Phone: +45 4288 1444, Fax: +45 4593 1634, e-mail: jd@ emi.dtu.dk
}

\begin{abstract}
This paper discusses examples on the use of polarimetric SAR in a number of Earth science studies. The studies are presently being conducted by the Danish Center for Remote Sensing ${ }^{\dagger}$. A few studies of the European Space Agency's EMAC programme are also discussed. The Earth science objectives are presented, and the potential of polarimetric SAR is discussed and illustrated with data collected by the Danish airborne EMISAR ${ }^{\dagger \dagger}$ system during a number of experiments in 1994 and 1995. The presentation will include samples of data acquired for the different studies.
\end{abstract}

\section{INTRODUCTION}

SAR has been considered a promising technology for numerous applications for close to 20 years. The advent of new and/or better sensors, both airborne and space borne, has improved the feasibility of performing qualitative studies on the usefulness of SAR with respect to operational applications and scientific studies. The strategy applied for these studies is to focus on few applications but mapping test areas multiple times to better understand temporal and environmental variations.

The Danish Center for Remote Sensing (DCRS) uses data from multiple sensors, but the principal sensor is EMISAR [1], which has been developed by the Department of Electromagnetic Systems (EMI). It is a fully polarimetric C- and L-band SAR covering a slant range swath of $9.6 \mathrm{~km}$ in the $2 \times 2$ m resolution mode. It is flown on Gulfstream G-3 aircraft of the Royal Danish Airforce. These twin engine jet aircraft are well-suited for SAR campaigns as they are fast (420 $\mathrm{kn})$, have a long range $(6000 \mathrm{~km})$, and typically operate at a high altitude $(41000 \mathrm{ft})$.

The system has been designed to exhibit excellent stability, and no calibration targets need to be deployed in the sites to be mapped due to a unique internal calibration system [2]. A calibration test site supporting fully polarimetric calibration has been established in co-operation with the Research Centre Foulum (RCF), Denmark. Usually, this site is mapped on the first and the last day of a mission in order to check and possibly correct the radiometric and polarimetric calibration of the data from the entire mission. A performance evaluation based on the Foulum data is found in [1].

The Danish Center for Remote Sensing is established and funded by the Danish National Research Foundation.

$\uparrow$ Development of EMISAR was sponsored by the Thomas 3. Thriges Foundation, the Danish Technical Research Cuunsil (STVF), the Royal Danish Air Force (RDAF), the Technical University of Denmark and the Joint Research Centre (JRC).
DCRS conducts research in both remote sensing technology and Earth science. Currently the latter includes seven study areas: Plant and Soil Mapping, Remote Sensing of Landscape Ecology, Determination of Aerodynamic Rougness, Microwave Sea Ice Signatures, Geologic Mapping in Greenland, Glacier Dynamics, and Sand Dune Dynamics. The Earth sciences are being pursued in collaboration with scientists outside DCRS.

Section 2 discusses the first five Earth science studies. The studies of Glacier Dynamics [3] and Sand Dune Dynamics are not discussed here, as they primarily rely on interferometry and not polarimetry. In Section 3 EMISAR's involvement in the EMAC campaigns is briefly addressed. Finally, the potential of using polarimetric SAR in the Earth sciences is discussed in Section 4.

\section{DCRS EARTH SCIENCE STUDIES}

\section{Plant and Soil Mapping}

The objective is to study the application of SAR to monitor agricultural crops, biomass, and soil physics. Mapping of extent, type, and state of agricultural crops are important for yield prediction and agricultural subsidiary policy enforcement. Soil moisture is an important but not very widely measured parameter in global climate models. It is a key factor in modeling evaporation, for calculating the capacity of land surfaces to absorb or release greenhouse gasses, and is expected to be a sensitive indicator of global change.

RCF is the DCRS science partner for this study, and the test site is the agricultural area surrounding RCF. Extensive in-situ measurements are conducted simultaneously with the acquisition of SAR data. The surface roughness is measured with a $2 \mathrm{D}$ scanning laser altimeter, and the soil moisture is measured using Time Domain Reflectometry (TDR). Spectral reflectance measurements in the visible and near infrared part of the spectrum are used to monitor biomass, leaf-areaindex, foliage distribution, and orientation. These data are used in concert with the polarimetric EMISAR data for DCRS's studies of classification and decomposition algorithms as well as electromagnetic backscatter modeling. The polarimetric classification work is supported by crop maps comprising hundreds of fields in the Foulum area.

\section{Remote Sensing of Landscape Ecology}

Habitat fragmentation and deterioration are primary causes of biodiversity reduction and species loss. Therefore it is desirable to be able to continuously monitor landscape ecology over large areas in order to detect natural and man-made 
changes, and to identify habitat types, estimate habitat quality, and quantify landscape patterns in terms of for instance patch size, adjacency, and connectivity. Since the features to be mapped are hedgerows, ponds, single large trees etc., a high spatial resolution is required. DCRS and the National Environmental Research Institute (NERI) studies the applicability of airborne polarimetric SAR in this field.

A 12 by $12 \mathrm{~km}$ test area at Kalø near NERI's Department of Wildlife Ecology is used for the experiments. The ground reference data include vegetation maps and maps of the distribution of chosen species of birds and mammals.

\section{Aerodynamic Roughness}

The objective is to assess the potential of measuring the aerodynamic roughness of the Earth's surface with polarimetric SAR and to develop appropriate data processing techniques. The aerodynamic roughness influences the ability of wind to initiate sand and dust movement, and it is an important parameter when modeling vertical transport of heat and water vapour, since increasing roughness implies increasing turbulence and thereby more vertical transport.

The experiments are conducted in the vicinity of Foulum, were the vertical wind profiles and turbulence over different surfaces are measured using anemometers. The wind data are supplemented with soil moisture and biometric measurements as these parameters affect the SAR data, too.

\section{Microwave Sea Ice Signatures}

This study aims at establishing a basis for monitoring sea ice conditions using microwave remote sensing techniques. In addition to its impact on the navigation over polar waters, sea ice has a huge influence on the heat exchange between the oceans and the atmosphere. Classification of the principal types of sea ice requires detailed information about their microwave signatures. In particular the polarimetric SAR signatures are studied and related to the scattering mechanisms at the ice surface and within the ice.

Sea ice data are collected in the Greenland Sea and off the coast of East and South Greenland. The EMISAR data are supplemented by satellite SAR data (ERS and RADARSAT), satellite radiometer data (SSM/I), and satellite visible and infrared data (NOAA-AVHRR, LANDSAT) as well as airborne microwave radiometer data (TUDRAD) and airborne visible data (video). Data are collected from different seasons and include nearly simultaneous observations.

\section{Geologic Mapping in Greenland}

The application of SAR for geologic mapping in Greenland is investigated by DCRS in co-operation with the Danish Lithosphere Centre (DLC). In its research plan DLC has concentrated on two themes. One is continental break-up, hotspots and possible mantle plumes. The other is plate boundaries and crustal accretion in the Precambrian. A firm understanding of the distribution of different rock lithologies is important for both research areas.
The questions to be answered are: 1) Is it possible to discriminate different rock lithologies using high-resolution polarimetric SAR imagery? 2) Can individual lava flows and lava sequences be distinguished and traced over extensive areas? 3) How do faults and dike swarms manifest themselves in polarimetric SAR imagery?

The test site is $400 \mathrm{~km} \mathrm{SW}$ of Scoresbysund in an area which is geologically well-known. Geologic maps have been generated through decades of field work. The terrain is characterised by an extreme topography as it also appears from the elevation contours of the geologic maps.

\section{EMAC}

The European Space Agency's European Multi-sensor Airborne Campaign (EMAC-94/95) is a programme providing support for the preparation of future satellite remote sensing programmes and their users [4]. The 1994 programme included coastal/ocean, agriculture, forestry and soils experiments with an optical multispectral scanner and two SAR systems. The NOrthern hemisphere climate Processes landsurface Experiment (NOPEX) was part of the EMAC programme. In 1995 the EMAC programme continued the NOPEX activities, but otherwise concentrated on snow and ice experiments in northern Europe where two SAR systems and two microwave radiometer systems collected data. Unlike previous snow and ice experiments the EMAC experiments emphasise the multi-temporal element.

In 1994 EMISAR collected polarimetric C-band data from the NOPEX test site at Uppsala, Sweden. In 1995 EMISAR collected both $\mathrm{C}_{-\mathrm{L}}$ and and $\mathrm{L}$-band data from the following test sites: NOPEX, the Gulf of Bothnia (sea ice), Oulu, Finland (snow), and Okstindan, Norway (glacier and snow). DCRS's role in the EMAC programme is to collect, pre-process, and calibrate the fully polarimetric, dual frequency EMISAR data. DCRS is not directly involved with the inte . pretation of the data.

\section{EARTH SCIENCE POTENTIAL}

In the following the potential of polarimetric SAR for various Earth Science disciplines is discussed on the basis of the above-mentioned EMISAR data. Table I summarises some of the conclusions by classifying the ability to measure a number of geophysical parameters.

DCRS has applied several pixel-based supervised classification algorithms to the Plant and Soil data sets from Foulum, including the Maximum Polarimetric Contrast algorithm and a maximum likelihood classifier based on the Complex Wishard distribution. The results are promising, but in order to discriminate crops with similar structures such as different cereals, multi-temporal data sets are required [5]. In addition, due regard should be paid to the fact that the incidence angle varies over the swath.

These studies have also shown that SAR is not as independent of weather as often stated. Factors like precipitation and wind have been found to have dramatic effects in vegetated areas. This is especially true for vegetation which like 
cereal has a vertical structure when no wind is present, and sufficient flexibility that the wind can change its orientation.

In combination with the in-situ measurements of soil moisture and surface roughness the Integral Equation Method (IEM) has been used to compute backscatter coefficients for a number of bare fields. These theoretical backscatter coefficients seem to be larger than those measured by EMISAR. Recent results indicate that one reason may be that the SAR signal is likely to be backscattered by a smoother subsurface layer [5]. The in-situ measured values of soil moisture and soil surface roughness agree very well with the estimates retrieved from the two co-polarised backscatter coefficients by using the empirical model developed by Dubois et al. [6]. It is desirable to complement the polarimetric SAR data by topographic data in order to correct the backscatter coefficient for the impact of the local incidence angle.

The application of polarimetric SAR data to map landscape ecology is very challenging. Unlike agricultural fields, the habitats to be classified are rarely homogeneous, e.g. meadows, mixed deciduous/coniferous forests. Also, the variety and the small extent of the features of interest complicate the use of SAR data. However, if the data is interpreted by an experienced human analyst many landscape classes and vegetation types can be discerned. For the forest studies the $\mathrm{L}$-band data seem to be preferable as it takes much larger biomass densities at L-band to saturate the backscatter which is generally an increasing function of the biomass per unit area. Also, at L-band the relative cross-pol to like-pol ratio seems to be an indicator of tree height and biomass.

Encouraging results have been obtained with respect to the aerodynamic roughness. For five selected surfaces a linear relationship has been found between the cross-pol backscatter coefficient and the logarithm of the aerodynamic roughness [7]. The $\mathrm{HH}$ polarisation is also highly dependent on the vegetation density and hence the aerodynamic roughness, while the vertical polarisation is more sensitive to the soil moisture. These results are based on EMISAR data from the NOPEX site and they are confirmed by Foulum data associated with a wheat field. Previously, a high correlation between aerodynamic roughness and backscatter coefficient has been reported for three different types of arid surfaces [8].

A fully polarimetric C-band data set of sea ice was collected off the East Greenland coast in March 1995. Simultaneous ERS-1 data, microwave radiometer data, and video data were recorded, allowing many different ice types to be identified and exposed to polarimetric signature analysis. It is evident that the discrimination capability is greatly improved when fully polarimetric data are available [9].

Less encouraging are the results from geologic mapping in Greenland. Indeed, structural features like faults, dike swarms, and lava bedding are reflected quite well in the SAR imagery, but a geologic classification cannot be performed on the basis of polarimetric data [10]. Due to the glacial activity in this area lithological differences do not reflect in the surface morphology measured by the SAR. It is noted that in other areas of the world, where the lithology is related to a unique morphology, it can be possible to infer some information about lithology from SAR data.
TABLE I. Polarimetric SAR measuring capability

\begin{tabular}{|l|c|c|c|}
\hline Parameter & High & Medium & None \\
\hline Soil moisture & $\mathrm{X}$ & & \\
\hline Surface roughness & $\mathrm{X}$ & & \\
\hline Aerodyn. roughness & & $\mathrm{X}$ & \\
\hline Crop type & $\mathrm{X}$ & & \\
\hline Ice type & $\mathrm{X}$ & & \\
\hline Lithologic rock type & & & $\mathrm{X}$ \\
\hline Geologic structure & & $\mathrm{X}$ & \\
\hline Landscape ecology & & $\mathrm{X}$ & \\
\hline
\end{tabular}

\section{CONCLUSIONS}

Results from 1994 and 1995 have shown that SAR is a very useful sensor for land cover mapping particularly for biosphere studies, SAR is also very useful in relation to both sea and inland ice studies. It has been found that for most studies there will be a significant temporal/environmental variation and it is thus very important for most studies to acquire more than one data set. Our present understanding is, however, that SAR seems to be less generally applicable for geological studies, mainly being of use for mapping morphology and also topography.

\section{REFERENCES}

[1] E. Lintz Christensen, J. Dall, N. Skou, K. Woelders, J. Granholm, and S.N. Madsen, "EMISAR: C- and L-band Polarimetic and Interferometric SAR", these proceedings.

[2] J. Dall, Niels Skou, E. Lintz Christensen, "Pulse-based Internal Calibration of Polarimetric SAR", IGARSS'94, Pasadena, California, USA, August, 1984.

[3] J.J. Mohr, S. Nørvang Madsen, and N. Reeh, "Applications of Interferometry to the Studies of Glacier Dynamics", these proceedings.

[4] E. Attema and M. Wooding, "EMAC Experimenters Handbook, Programme for 1995", ESTEC.

[5] H. Skriver, J. Ji, J.Dall, K. Woelders, and A. Thomsen, "A Multi-Temporal and Multi-Frequency Study of Polarimetric Signatures of Soil and Crops", in press, EUSAR'96, Köningswinter, Germany, March, 1996.

[6] P. Dubois, J. van Zyl, and T. Engman, "Measuring Soil Moisture with Imaging Radar", IEEE Trans. Geoscience and Remote Sensing, vol. 33, pp. 915-926, 1995.

[7] A. van de Griend, "Progress report for the Forest Dynamo Project", EU report, 44 pp.

[8] R. Greeley and D.G. Blumberg, "Preliminary Analysis of Shuttle Radar laboratory (SRL-1) Data to Study Aeolian Features and Processes", IEEE Trans. Geoscience and Remote Sensing, vol. 33, pp. 927-933, 1995.

[9] B.B. Thomsen, L. Toudal Pedersen, and H. Skriver, "CBand Polarimetric Signatures of Winter Sea Ice", these proceedings.

[10] J. Dall, S.N. Madsen, C.K. Brooks, and T. Nielsen, "Geologic Mapping in Greenland with Polarimetic SAR", IGARSS'95, Florence, Italy, August, 1995. 